\title{
Incremental dynamic analysis of the long- span continuous beam bridge considering the fluctuating frictional force of rubber bearing
}

\author{
Man Liao ${ }^{1}$, Bin Wu ${ }^{1}$, Xianzhi Zeng ${ }^{1}$ and Kailai Deng ${ }^{1,2^{*}}$ (1)
}

* Correspondence: kailai.deng@ swjtu.edu.cn

'Department of Bridge Engineering, Southwest Jiaotong University, Chengdu 610031, China ${ }^{2}$ Key Laboratory of High-speed Railway Engineering, Ministry of Education, Southwest Jiaotong University, Chengdu 610031 People's Republic of China

\begin{abstract}
In the seismic design of long-span bridges, the classic bi-linear model was used to simulate the frictional restoring force of the rubber bearings. However, in actual earthquake, the rubber bearing suffered fluctuating axial pressure in earthquake, even separated from the beam when vertical component of the earthquake was too strong. Employing the bi-linear model for the bearing may incorrectly estimate the seismic response of the bearings, as well as the whole bridge. This paper developed a nonlinear frictional bearing model, which can consider the variation of the frictional restoring force in the bearings, even the separation with the beam in vertical directions. A typical continuous beam bridge was modeled in ABAQUS, and incremental dynamic analysis was conducted for the quantitative comparison of the seismic responses using different bearing models. The intensity measure was selected as the ratio of the peak ground acceleration (PGA) in the vertical direction to the PGA in the horizontal direction. The analysis results indicated that the different bearing model led to the significant different seismic response for the bearings and piers, even the vertical component was small. The bi-linear bearing model would underestimate the seismic demand of the bearing and piers.
\end{abstract}

Keywords: Rubber bearing, Fluctuating frictional restoring force, Incremental dynamic analysis, Vertical component, Seismic design

\section{Introduction}

Rubber bearings were widely used in bridge engineering owing to its economy, durability and easy construction, i.e. basin-type rubber bearing and panel-type rubber bearing. In general, the rubber bearing has very large compressive stiffness and load-carrying capacity in vertical direction, and provides frictional restoring force in horizontal directions (Yang et al. 2017; Jiang et al. 2019; Ding et al. 2019). In practical design, the rubber bearing was simplified as a linear spring both in vertical compression and tension. In horizontal direction, many mechanical models were developed to simulate the friction restoring force of rubber bearings, i.e. equivalent linear model, bi-linear model,

(c) The Author(s). 2021 Open Access This article is licensed under a Creative Commons Attribution 4.0 International License, which permits use, sharing, adaptation, distribution and reproduction in any medium or format, as long as you give appropriate credit to the original author(s) and the source, provide a link to the Creative Commons licence, and indicate if changes were made. The images or other third party material in this article are included in the article's Creative Commons licence, unless indicated otherwise in a credit line to the material. If material is not included in the article's Creative Commons licence and your intended use is not permitted by statutory regulation or exceeds the permitted use, you will need to obtain permission directly from the copyright holder. To view a copy of this licence, visit http://creativecommons.org/licenses/by/4.0/. 
modificatory bi-linear model and Bouc-Wen model et al. (MHURDPPC 2018; Bouc 1967; Wen 1976; Park et al. 1986). The classical bi-linear model was one of the most commonly used models in bridge engineering owing to its simplicity and efficiency (Wei et al. 2018; Mazda et al. 2016). In the bi-linear mechanical model, yielding force was assumed to be the product of its gravity load and the frictional coefficient at the contact interface. The bi-linear model was provided by many design software, and convenient for the numerical calculation (MIDAS Soft 2019; Computers and Structures 2018). At present, the correlated horizontal and vertical ground motions affected behavior of rubber bearing (Zhang et al. 2009). When the ground motion had strong vertical component, the vertical load in the bearing varied significantly, resulting in the fluctuating restoring force. In this case, the simplified bi-linear model could not reproduce the actual behavior of the rubber bearing.

The rubber bearing in Higashi-Kobe Bridge separated from the beam in Kobe earthquake. The beam lifted up for about $50 \mathrm{~cm}$ and the bearings failed under such big pounding load (Wilson 2003). In Wenchuan earthquake, the separation between the bearing and beam was also observed in Miaoziping bridge (Du et al. 2008). The residual relative movement of beam-pier was up to $46 \mathrm{~cm}$. The rubber bearing including the concrete pad were completely damage under enormous pounding. Eröz and DesRoches (2013) noticed the fluctuation of vertical load in friction pendulum system (FPS), and analyzed the influence from the vertical effect. Without considering the varying vertical load, the stress and deformation of the piers would be underestimated. Jiao and Li (2018) adopted the compression-only model for the rubber bearing, and the beambearing separation was observed in the time history analysis. Li et al. (2018) developed a model involving the varying frictional restoring force in the friction pendulum system. These analysis results indicated the weakened energy dissipation capacity because of the fluctuating vertical load. Many more studies also pointed that the fluctuated axial load even separation of the rubber bearing of friction pendulum system could significant affect the seismic performance of the bridges (Wei et al. 2014; Jiang et al. 2020; Khoshnudian and Motamedi 2013).

The above studies pointed out that the simplified bi-linear bearing model may lead to the obviously incorrect estimation of the earthquake response (Kong et al. 2015; Liu et al. 2016; Marin-Artieda et al. 2009). Especially, the seismic demand of the bridges, i.e. the strength and drift demand of the piers, and the anchorage strength of the bearings, may be underestimated.

This paper developed a nonlinear frictional bearing model, which employed the frictional model for the bearings, involving the fluctuation of the normal pressure and the corresponding variation of the frictional restoring force. Simultaneously, the quantitative comparison on the seismic response of the continuous beam bridge using bi-linear bearing model and frictional bearing model were conducted. A typical 3-span continuous beam bridge was built in ABAQUS, and the incremental dynamic analysis were carried out. The intensity ratio (IR) of peak ground acceleration (PGA) in vertical direction to the PGA in horizontal direction was employed as the intensity measure. The responses of the bearing and pier were discussed under different $I R$. The bi-linear model underestimated the seismic response of the bridge in all aspects, i.e. the capacity demand of bearings, the peak deformation and strain of the piers. According to the analysis results, the design suggestions were provided when using the result from the simple bi-linear model. 


\section{Seismic performance analysis}

\subsection{Benchmark bridge}

A typical 3-span continuous beam bridge was selected as the representative bridge. The bridge is located in the site of class II in Chinese seismic design code, which had the characteristic period of $0.40 \mathrm{~s}$ and the intensity of the fundamental peak ground acceleration (PGA) of $0.2 \mathrm{~g}$ (MTPRC 2020). Thus, in this area, the design-based earthquake (DBE) and maximum considered earthquake (MCE) corresponded to the PGAs of $0.2 \mathrm{~g}$ and $0.34 \mathrm{~g}$ for this bridge. The dimensions are presented in Fig. 1a. The continuous beam bridge with a total length of $318 \mathrm{~m}$ and the span arrangement of $85 \mathrm{~m}-148 \mathrm{~m}-85$ $\mathrm{m}$. The twin piers were used in the bridge, and the abutments were set at two ends of the main beam. The main beam had the varying single box single chamber crosssection and the pier had the constant box section, as shown in Fig. 1b and c. Two kinds of basin-type rubber bearings were selected in the bridge based on its gravity load, 12 basin-type rubber bearings in total. Table 1 lists the mechanical properties of the bearings, where the GPZ8SX bearing, called middle bearing, was used on the main piers. And the GPZ2SX bearing, called side bearing that was used on the abutments.

\subsection{Modeling in ABAQUS}

The finite element model was developed in ABAQUS, as shown in Fig. 2. The multilayer shell elements were used in the simulation of main beam, including the flanges, webs and diaphragms. The reinforcement in the main beam was introduced as the sectional integral layers. The piers were simulated by the B31 elements (3D Timoshenko beam elements). The reinforcement in the piers were inserted by the sectional integral points. The nonlinear spring was used to reproduce the behavior of the basin-type rubber bearings. Two different models were used for the basin-type rubber bearings, i.e. bi-linear bearing model and frictional bearing model, as shown in Fig. 3. The bi-linear

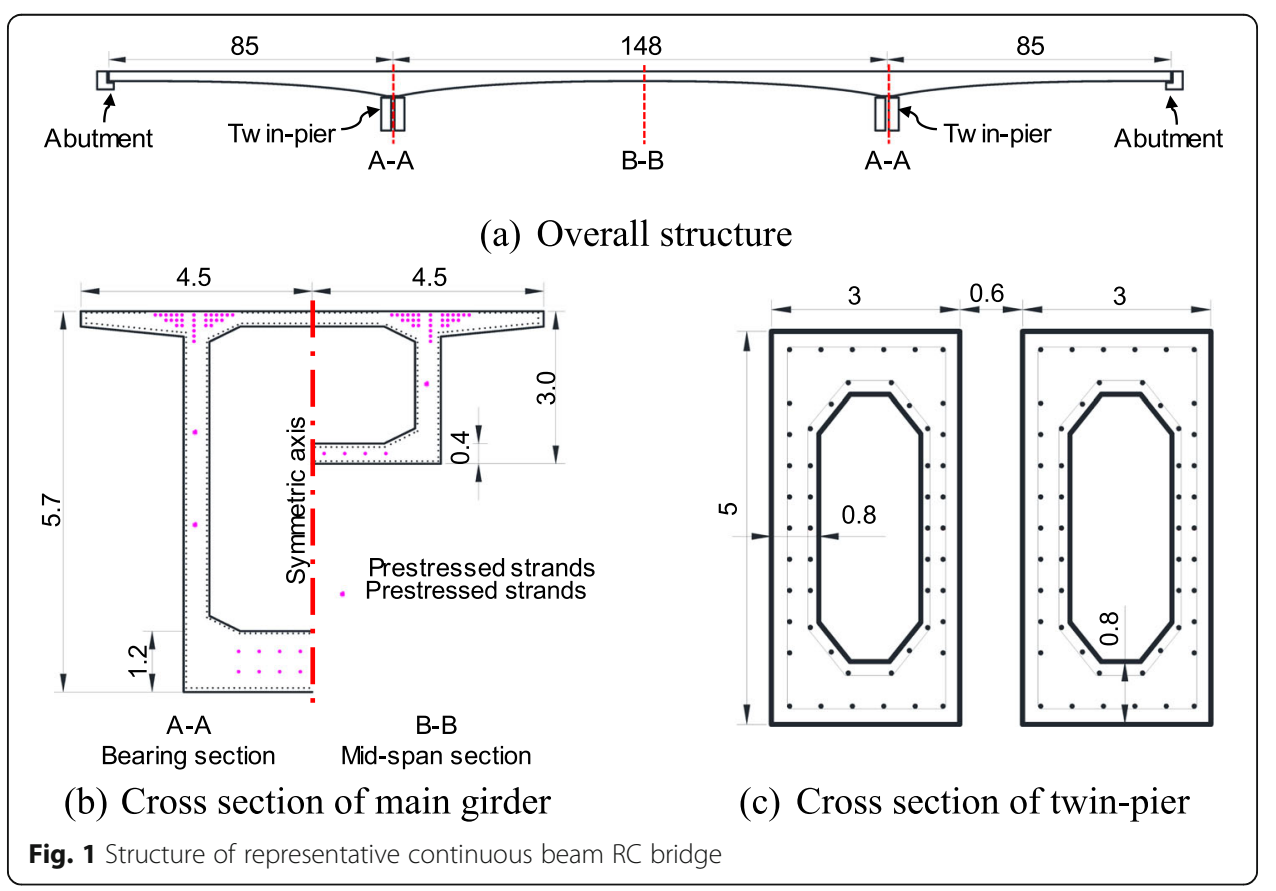


Table 1 Mechanical parameters of the basin type rubber bearing

\begin{tabular}{llllll}
\hline $\begin{array}{l}\text { Rubber } \\
\text { bearing }\end{array}$ & $\begin{array}{l}\text { Maximum } \\
\text { vertical load /kN }\end{array}$ & $\begin{array}{l}\text { Subjected } \\
\text { gravity load } / \mathbf{k N}\end{array}$ & $\begin{array}{l}\text { Vertical stiffness } \\
/(\mathbf{k N} / \mathbf{m m})\end{array}$ & $\begin{array}{l}\text { horizontal stiffness } \\
/(\mathbf{k N} / \mathbf{m m})\end{array}$ & $\begin{array}{l}\text { Frictional } \\
\text { coefficient }\end{array}$ \\
\hline GPZ8SX & 8000 & 6904 & 1000 & 103.5 & 0.03 \\
GPZ2SX & 2000 & 1926 & 1000 & 28.9 & 0.03 \\
\hline
\end{tabular}

bearing model provided linear elasticity in vertical direction and the bi-linear hysteretic models in horizontal directions. The yielding force was a constant value, i.e. the product of gravity load and frictional coefficient. The post-yielding stiffness was zero.

In the vertical direction, the compressive-only model was applied to the frictional bearing. When subjected to compressive deformation, the frictional model was applied with the common stiffness to reproduce its load-carrying capacity. While subjected to tensile deformation, a very small stiffness was employed to simulate the possible separation of bearing. The vertical behavior of bearing was shown in Fig. 3(b). In horizontal directions, the frictional force could change with the vertical force. The formula of the horizontal frictional behavior can be described by Eq. (1) (Systèmes 2007), where, $F_{H}(t)$ is the horizontal frictional force, $\mu$ is frictional coefficients, $W(t)$ is the vertical force, and $D_{H}$ is sliding displacement. Of course, in case of the occurrence of bearing separation, i.e. $W(t)$ equaling to 0 , the frictional restoring force $F_{H}(t)$ must be zero (Zhao et al. 2021). The frictional bearing model is more realistic to the actual behavior of the bearings in earthquake.

$$
F_{\mathrm{H}}(t)=\mu W(t) \operatorname{sgn}\left(\dot{D}_{\mathrm{H}}\right)
$$

The material constitutive models of HRB400 rebar and C60 concrete are illustrated in Fig. 4. The concrete model considers the strength and stiffness degradation of concrete, while it neglects the tensile stress of the concrete. The constitutive law of HRB400 rebar obeys the Clough constitutive model, which can well reproduce the pinching effect of the RC component under cyclic deformation (Deng et al. 2019).

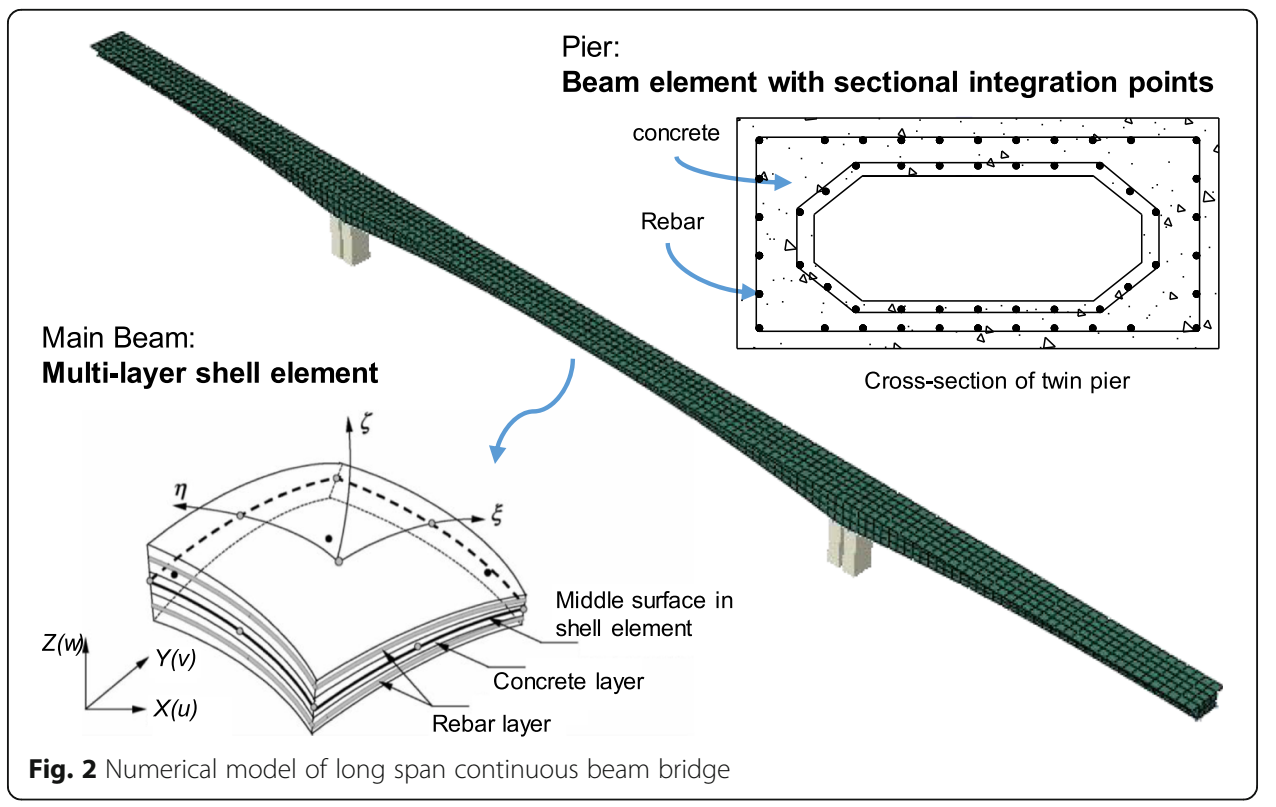




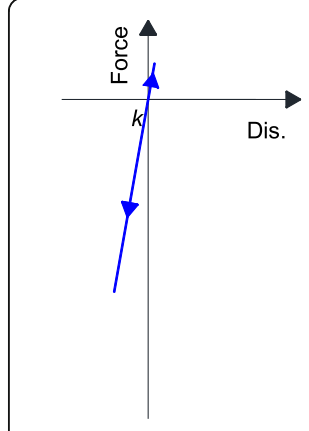

(1) Vertical direction

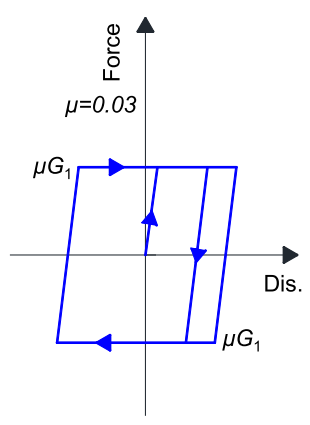

(2) Horizontal direction

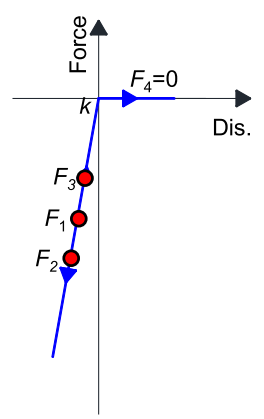

(1) Vertical direction

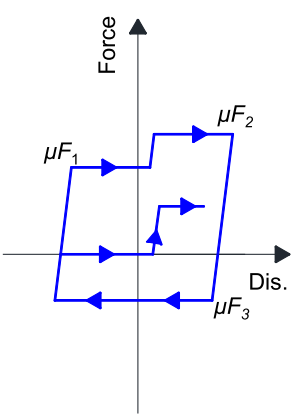

(2) Horizontal direction

(a) Conventional bi-linear model

(b) Fluctuating frictional restoring force

Fig. 3 Two hysteretic models of basin-type rubber bearing

\subsection{Ground motion records}

The mean squared error (MSE) method provided by the PEER ground motion database was used to select the ground motion (GM), which was widely used in the selection of GMs (Xu et al. 2018; Ji et al. 2017). Seven ground motions are generated by fitting the design response spectrum, as shown in Fig. 5a. Figure 5b compares the response spectra of the seven GMs with the target spectrum, which delivered good agreements (JTG/ $\mathrm{T}$ 2231-01-2020). In the incremental dynamic analysis, the GMs were input from both longitudinal and vertical directions.

Practically, the horizontal restoring force of the friction bearing presented strong dependency to its vertical force, usually proportional to the vertical force with the constant frictional coefficient. However, the vertical force in the bearing was not constant, especially subjecting to the earthquake with strong vertical component. On the other hand, the classic bi-linear model of friction bearing just provided the constant horizontal restoring force regardless of its vertical force. Using frictional model for bearings may cause obviously different seismic response against using classic bi-linear model, especially under the earthquakes with strong vertical components. Thus, the intensity ratio $(I R)$, defined as the PGA in the vertical direction over by the PGA in the

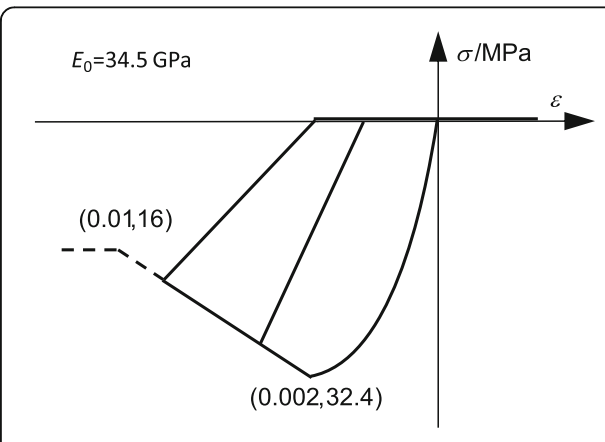

(a) C60 concrete

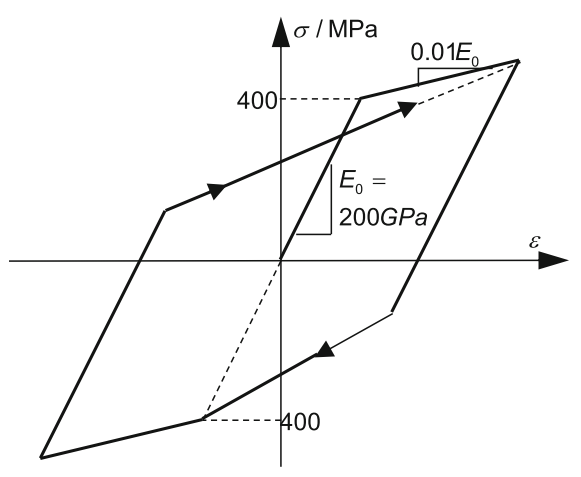

(b) HRB400 rebar

Fig. 4 Two hysteretic models of basin-type rubber bearings 


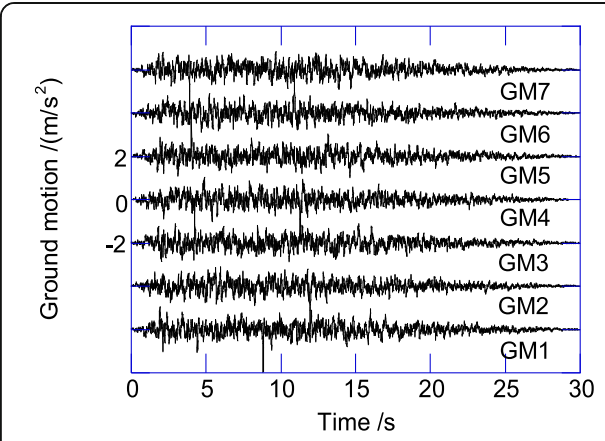

(a) Ground motion records

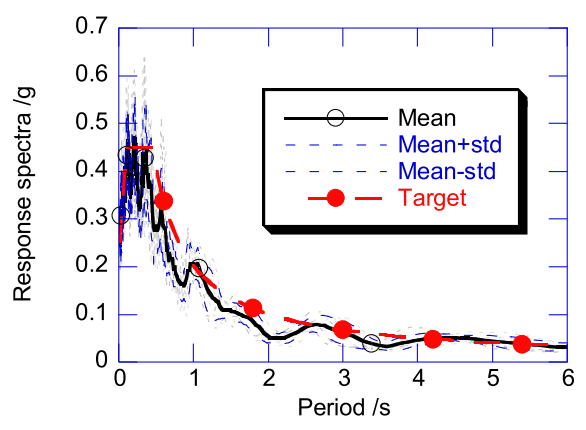

(b) Response spectra

Fig. 5 Generated seven ground motions and response spectra

longitudinal direction, was taken as the intensity measure in the incremental dynamic analysis.

\section{Analysis results}

\subsection{Result under required IR}

According to the Guidelines for Seismic Design of Highway Bridges in China (MTPRC 2008), the required $I R$ is 0.65 . By taking GM1 with $I R$ equaling to 0.65 as the representative case, Fig. 6 compares the vertical load history on the bearings. For the middle bearings, the fluctuation was not significant, and the maximum vertical loads were 9.14 $\mathrm{MN}$ and 8.45 $\mathrm{MN}$ when using the bi-linear bearing model and frictional bearing model respectively. However, the difference in the side bearings was evident. The side bearing with the bi-linear bearing model, even 0.39 $\mathrm{MN}$ tensile force was observed, which represented the bearing was separated from the beam. The comparison on hysteretic curves of the bearings are illustrated in Fig. 7. For the middle bearing, there's little difference here. The peak restoring force in the frictional bearing was $249 \mathrm{kN}$, about $20 \%$ larger than the yielding force in the bi-linear bearing. Furthermore, the maximum deformation of the frictional bearing model was 1.19 times of that in bi-linear bearing model. In addition, the differences between bi-linear bearing model and frictional bearing model in side bearings were more significant. The overall shape of the hysteretic curve of the frictional bearing model was not saturable parallelogram. The restoring

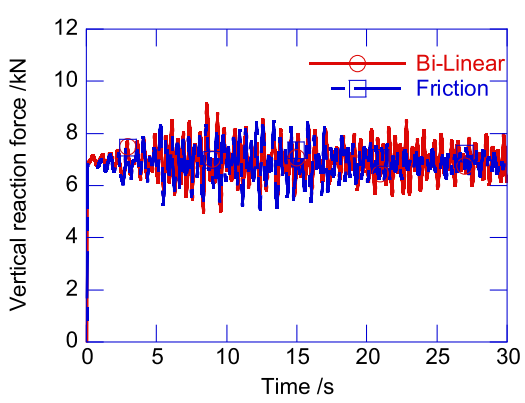

(a) Middle bearing

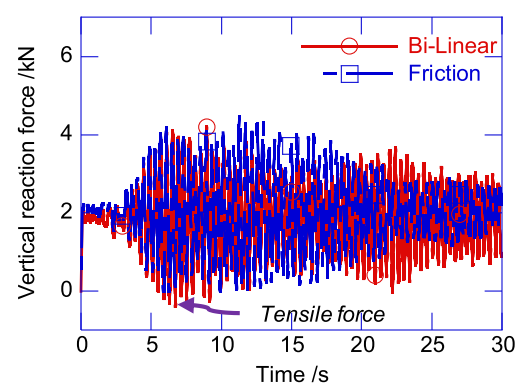

(b) Side bearing

Fig. 6 Comparison on vertical load history $(\mathrm{GM} 1, \eta=0.65)$ 


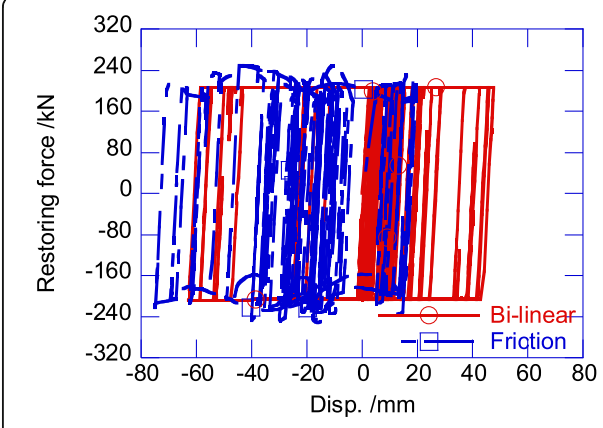

(a) Middle bearing

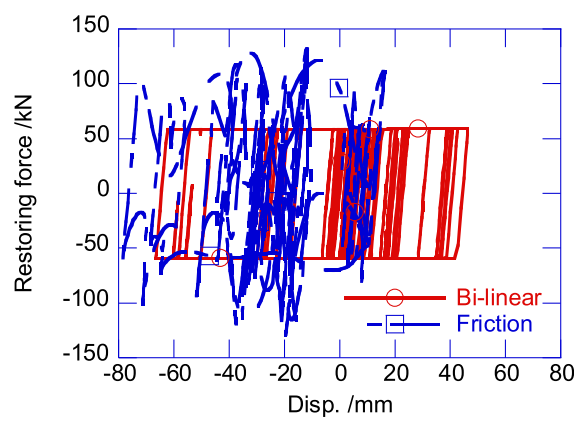

(b) Side bearing

Fig. 7 Comparison on hysteretic curves $(\mathrm{GM} 1, \eta=0.65)$

force in the frictional bearing model experienced significant variety during the whole earthquake. The peak restoring force was up to 2.24 times of the yielding force in the bi-linear model. The deformation of the frictional bearing model was about 1.18 times that of the bi-linear bearing model. Figure 8 compared the energy dissipation capacities. The difference in side bearings was not very obvious. For the middle bearings, the frictional bearing dissipated more energy than bi-linear bearing, i.e. nearly $20 \%$ enhancement.

As shown in Fig. 9, with the frictional bearing model, the twin-pier subjected to the larger peak tensile strain and compressive strain, as well as the larger drift of the pier top. That is, nearly $131 \mu \varepsilon$ (micro-strain) can be obtained by employing the frictional bearing model, demonstrating that the piers already cracked at MCE intensity with $I R$ equaling to 0.65 . However, the bi-linear bearing model could not reflect the cracking. In consequence, employing the bi-linear model as a simplified model for the rubber bearings would underestimate the seismic risk of the bridge, and result in an unsafe design of the bearings and piers.

\subsection{Results of IDA}

Some near-fault ground motions have delivered the IRs were greater than 1.0 (Bozorgnia and Niazi 1993; Zhou et al. 2003; Chen et al. 2014). To extend the utility of this

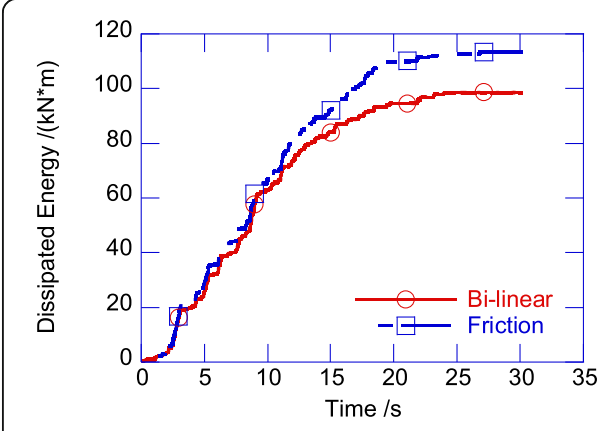

(a) Middle bearing

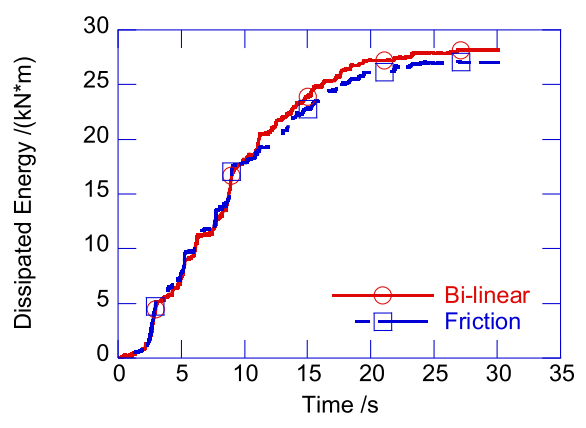

(b) Side bearing

Fig. 8 Comparison on energy dissipation capacity curves $(G M 1, \eta=0.65)$ 


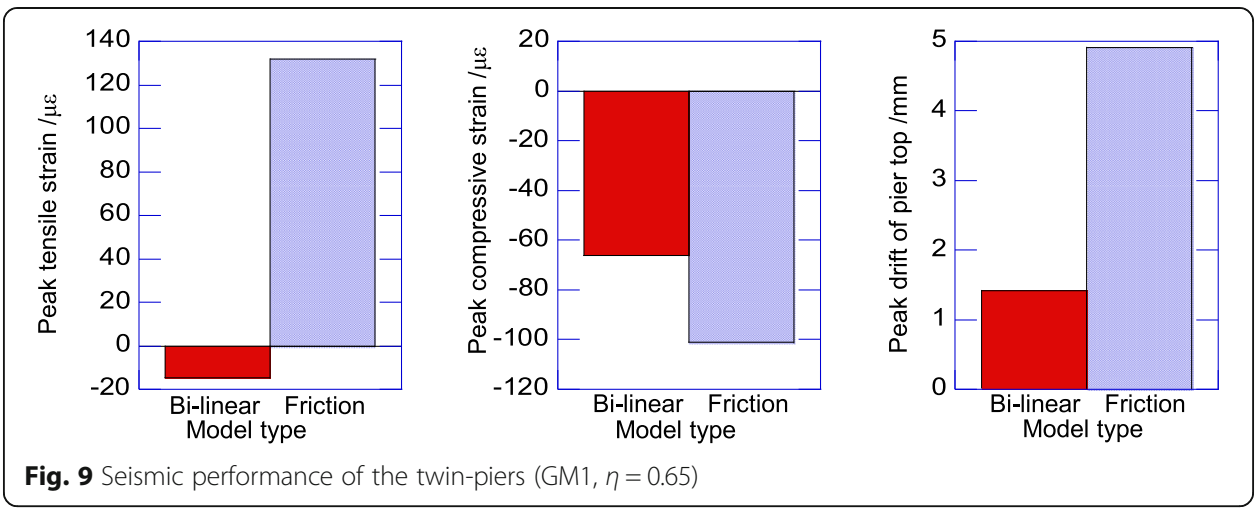

study, the $I R$ changed from 0 to 3.0 in this paper. The peak vertical loads on the bearings were illustrated in Fig. 10, including the peak compressive and tensile loads. According to Fig. 10a and b, with the increase of the $I R$, the maximum vertical load increased. But the maximum vertical load was not linear proportional to the $I R$. When the $I R$ increased from 0 to 3.0, the peak compressive load increased quickly. When the $I R$ surpassed 1.35, with the $I R$ growth, it couldn't cause significant increase of the peak compressive load and tensile load. Furthermore, the increase in the middle and side

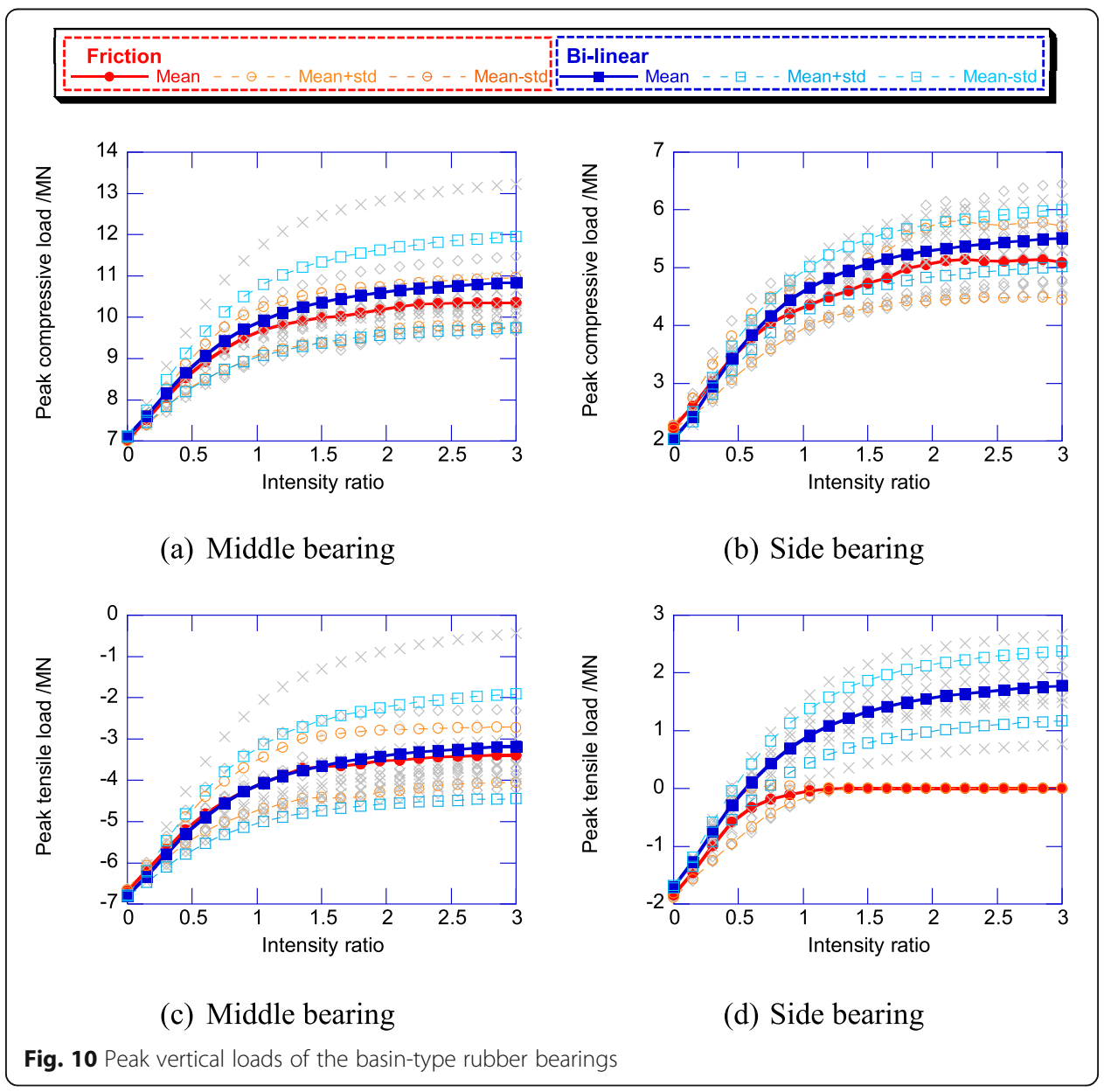


bearings were not consistent. For middle bearing under $I R$ equaling to 3.0, the maximum vertical load was about 1.51 times of the gravity load. While side bearing subjected to 2.54 times of the gravity load under the same $I R$.

Figure 10c and d shows the peak tensile loads on the bearings, where negative value means no tensile load occurred on the bearings throughout the earthquake. For the middle bearing, no tensile load occurred in regardless of the bearing models. However, for the side bearing, bi-linear bearing model experienced remarkable tensile load when the $I R$ was larger than 0.6 , which was impossible to occur on the actual basin-type rubber bearing. The elastic property in the vertical direction simulated by bi-linear model may overestimate the tensile force in the pier or abutment. Nevertheless, for the side bearing with friction model, no tensile load occurred. When the $I R$ was larger than 1.35 , the mean value and standard deviation were 0 , indicating that the main beam separated from the side bearing. This result is closer to the actual situation, and the separations were observed in Wenchuan earthquake (Li et al. 2008). According to the vertical load analysis, the fluctuation of the vertical load was evident, even the separation of beam and bearing would occur on the side bearing. As a result, selecting the bearing type just based on its shared gravity load is not a conservative way to guarantee its safety, especially for the side bearing.

The maximum restoring force of the bearings are presented in Fig. 11. Obviously, the maximum restoring force of the bearing assigned with the bi-linear model was a constant value, equaling to the yielding force. The vertical load didn't have any influence on the maximum restoring force in the bi-linear bearing model. For the bearing assigned with friction model, the maximum restoring force increased with the IR. Moreover, the maximum restoring forces in the frictional bearing model were proportional to the peak compressive load. The correlation coefficients for the middle and side bearings were 0.99 and 0.97 respectively. Therefore, the peak vertical compressive load was the controlling factor for the maximum restoring force. Compared with the yielding force in the bi-linear model, the maximum restoring force obtained from the friction model were respectively 1.57 times and 2.41 times for the middle and side bearings. Thus, the excessive frictional force should be considered when designing the connection for the bearings.

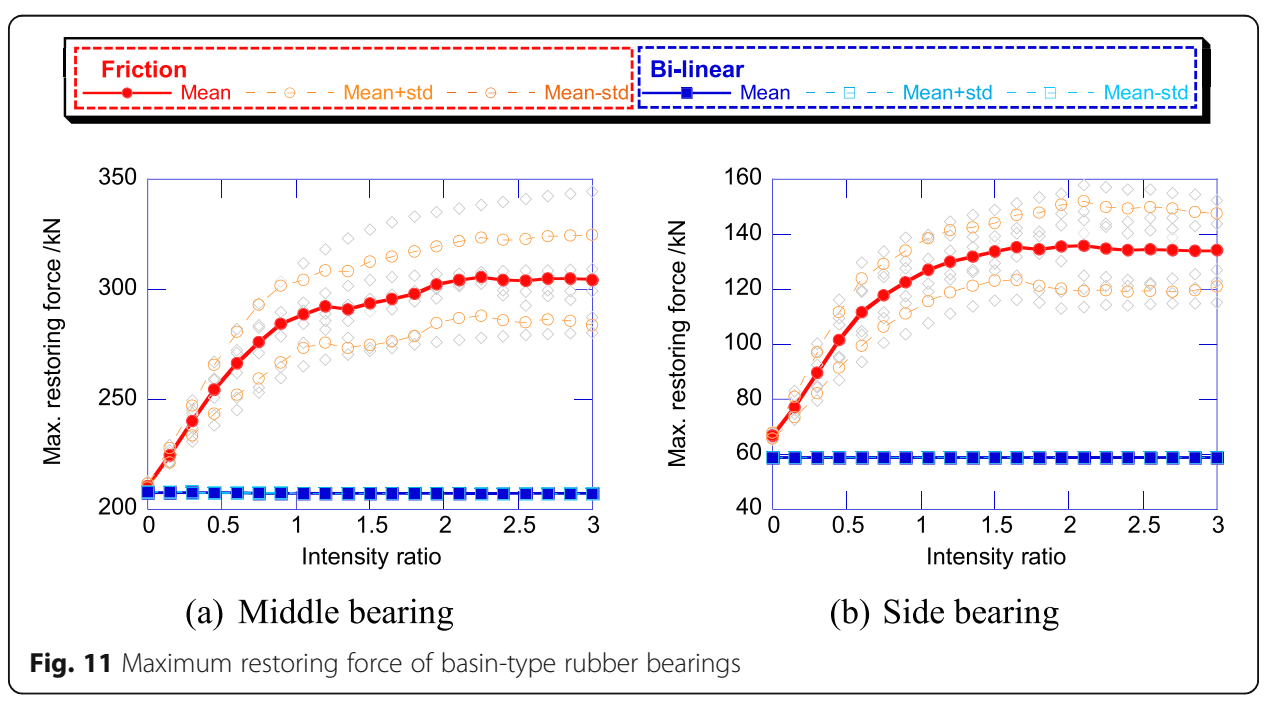


Fig. 12 compares the maximum deformation of middle bearing and side bearing. Apparently, employing the bi-linear model would result in a smaller deformation of the bearings, both for middle and side bearings. When the $I R$ equaled to zero, the difference was negligible. The deformation of the bearings gradually decreased with increasing the $I R$. On the other hand, adopting different bearing models would lead to the differences increase as well. At the $I R$ of 1.95 , the differences of the maximum deformation were up to $17.3 \mathrm{~mm}$ and $20.44 \mathrm{~mm}$ for middle and side bearings respectively. The arrow in Fig. 12 shows the occurrence of the maximum difference. The deformations obtained in the bi-linear bearing model were just half of those obtained in the frictional bearing model in the most unfavorable case. Further increase in the $I R$ would slightly reduce the difference. Hence, employing the bi-linear bearing model for the basin-type rubber bearing would underestimate the bearing deformation compared with employing the friction model for the bearings, especially when the $I R$ equaled to 1.95 . The underestimation was nearly half at all the IRs. It can be concluded that employing the bi-linear model for the bearings may lead to the inadequate design of the bearing deformation capacity.

The energy dissipation capacities of the bearings declined with increasing $I R$, both for the frictional and bi-linear bearing models, as shown in Fig. 13. For the middle bearings, the frictional bearing model had larger energy dissipation than the bi-linear bearing model. The enlarged restoring force could contribute more energy dissipation, and the contribution was more evident than those caused by the reduced restoring force. For the side bearings, the energy dissipations of the friction and bi-linear bearings were almost same. The contribution from the enlarged friction force may be accidently equaling to the loss from the reduced restoring force. Overall, employing the frictional bearing model would have a larger energy dissipation capacity.

The maximum drifts of the pier top were illustrated in Fig. 14. The variation trends of the maximum drift with the $I R$ were completely different when employing different bearing models. When employing the friction model, the maximum drift of pier top increased with the $I R$, while it decreased when employing the bi-linear bearing model. Furthermore, the drift obtained with the bi-linear bearing model was much smaller

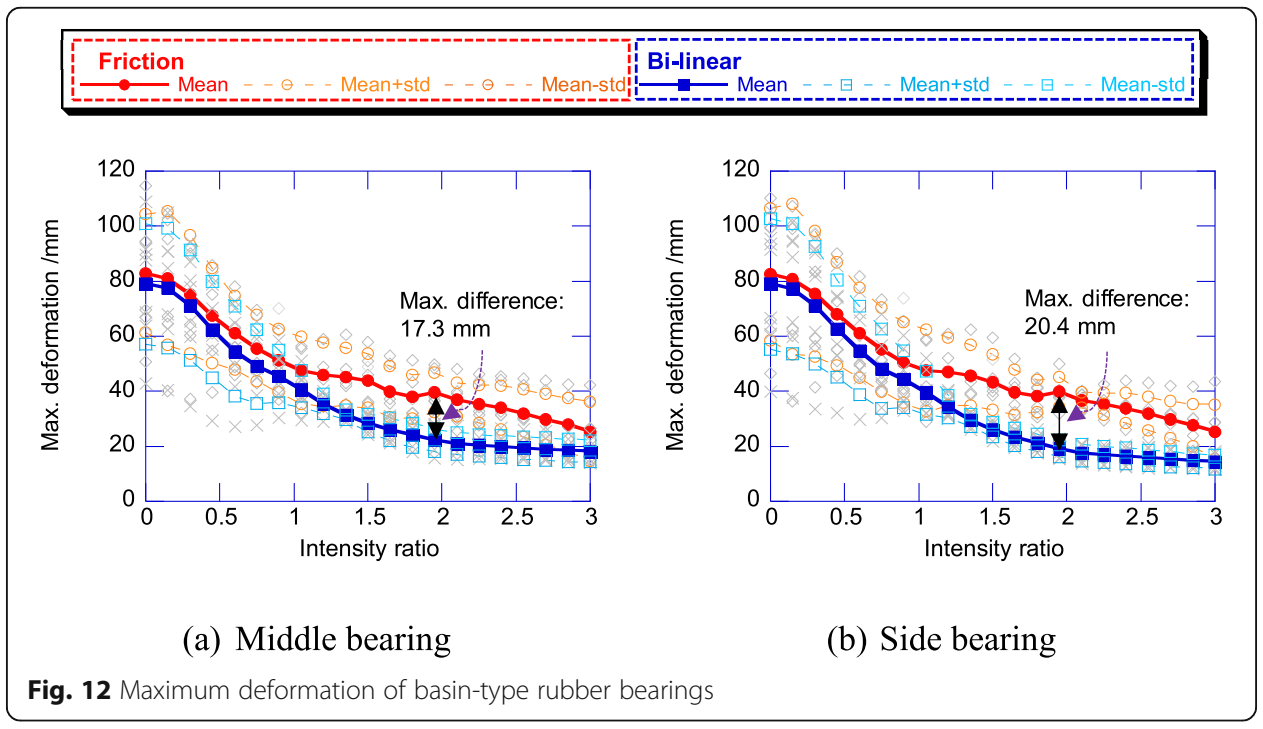




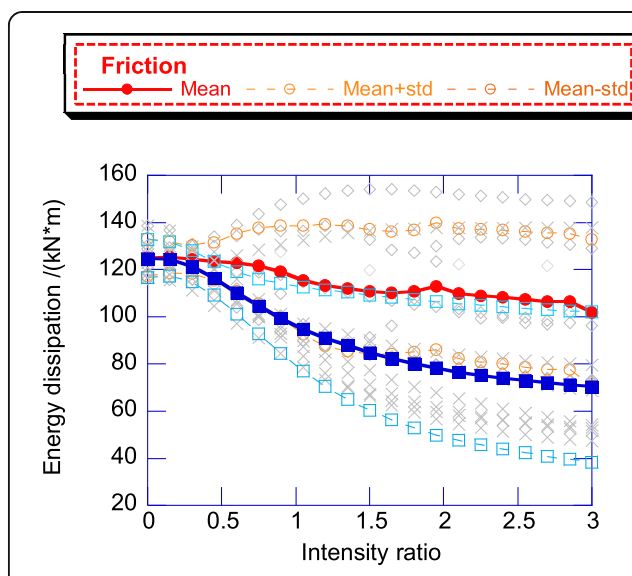

(a) Middle bearing

Bi-linear

Mean -

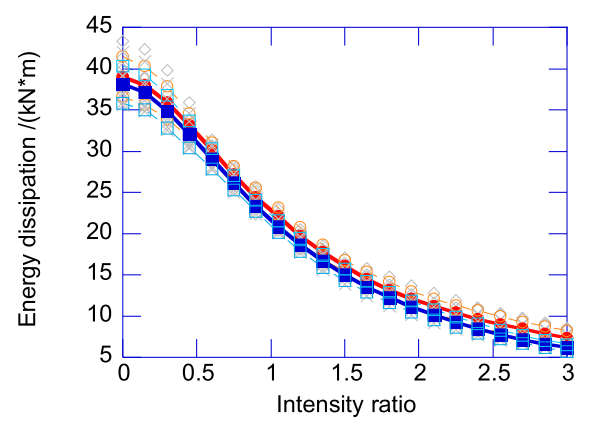

(b) Side bearing

Fig. 13 Energy dissipation of basin-type rubber bearing

than that obtained with the friction model. This may be caused by the larger maximum restoring force of the bearing with friction model. It is understandable that the larger shear force in the bearings corresponded to the larger moment at bottom section and lateral drift at the pier top.

Furthermore, the standard deviation obtained from the bi-linear model was much smaller than that obtained from the friction model. When employing the bi-linear

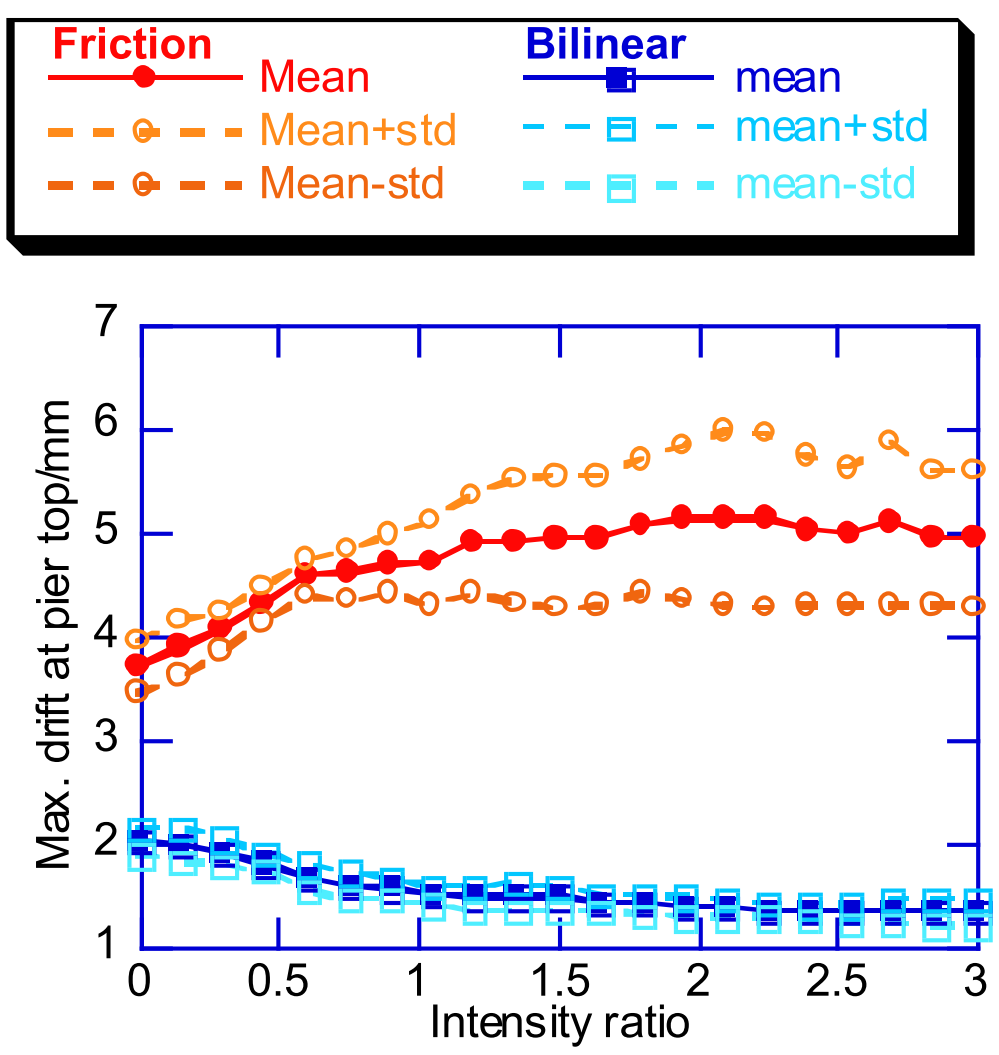

Fig. 14 Maximum drift of pier top 
model, the maximum possible shear force on the piers equaled to the sum of the bearing yielding force. Under all the GMs, the bearing yielded and the pier may subject to the same peak shear force, i.e. doubled yielding force of the middle bearings in this case. The vertical component of GM had little impact on the pier deformation. Conversely, when employing the friction model, the vertical component of GM could significantly affect the peak compressive load on the bearing, and then affect the maximum shear force in the bearings. Hence, the pier would sustain different shear force under different $I R$. The bi-linear bearing model had obvious defect in revealing the effect of the vertical component of GM on the pier performance. Consequently, employing the bi-linear model for the bearing may underestimate the seismic demand of the piers.

This same problem was also reflected on the peak strain at the bottom section of the piers, as shown in Fig. 15. Compared with the bi-linear model, the peak compressive strain and tensile strains of frictional bearing model were both larger. The bi-linear model may underestimate the earthquake risk. For example, the cracking strain of C50 concrete was $78 \mu \varepsilon$. The results indicated the crack would occur on the pier under all the IRs with the friction model. But the bi-linear model couldn't deliver the crack performance of the pier. Similarly, the peak compressive strain obtained with the friction model was also larger than that obtained with the bi-linear model. When the IR surpassed 1.05, the peak compressive strains obtained from the friction model was about 1.7 times of those obtained from the bi-linear model.

Even without vertical component of the GM, the maximum curvature was 3 times larger when using friction model alternative instead of the bi-linear model, as shown in Fig. 16. With the $I R$ increasing, the difference became larger. For example, the ratio between friction model and bi-linear model was up to 5.37 at the $I R$ of 2.1. Generally considering the maximum drift, pier top and curvature, it can be concluded that the bilinear model would significantly underestimate the strain in the pier. The results of the strain at pier bottom further indicate that the bi-linear model of the bearing is a simplified way of being unsafe for the seismic performance assessment.

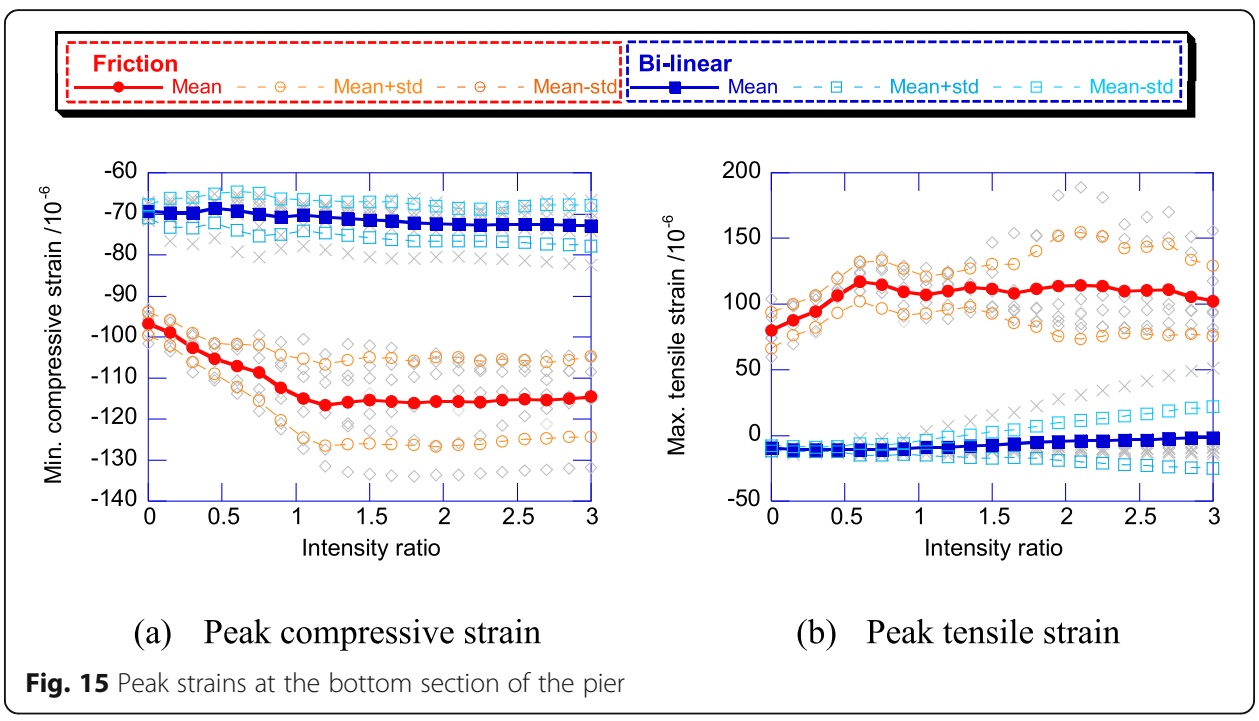



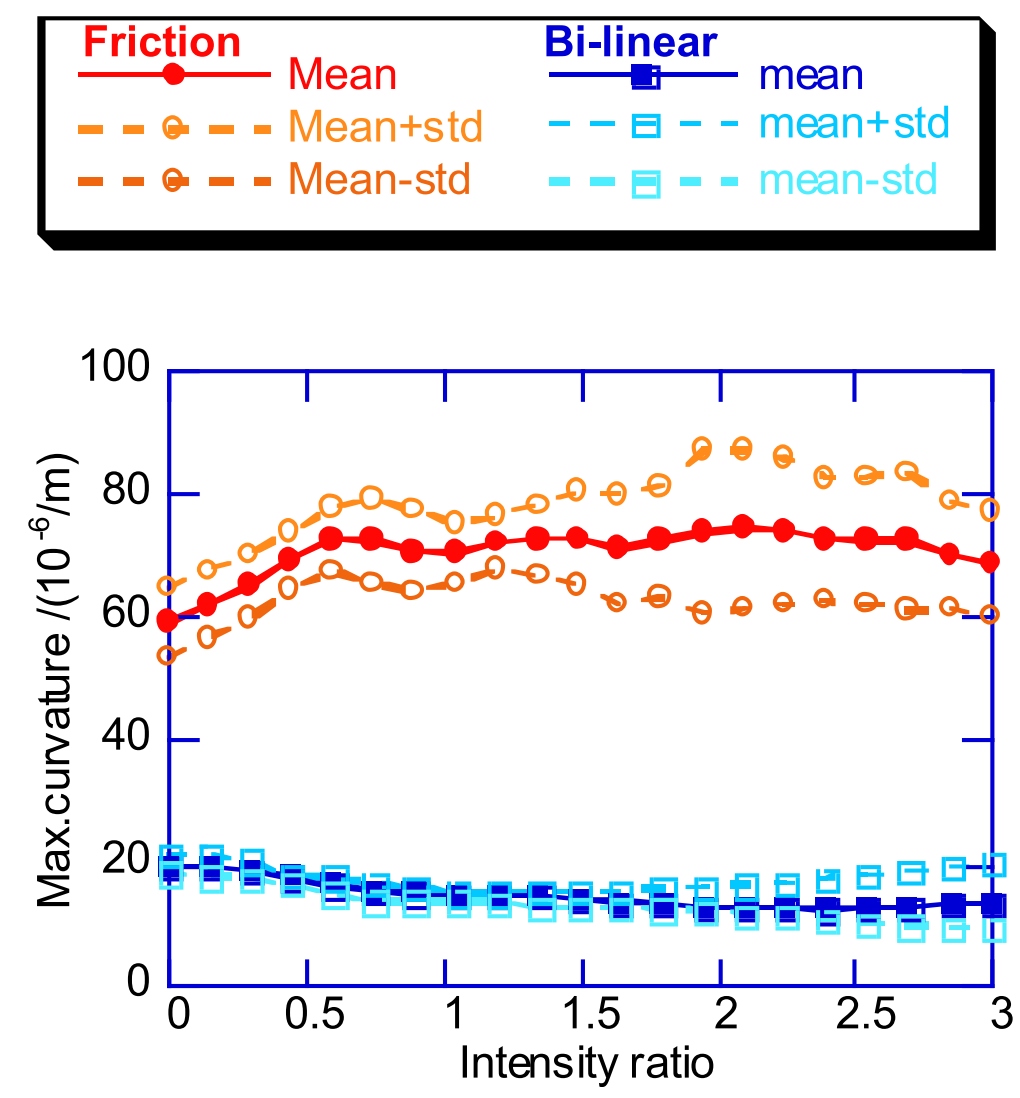

Fig. 16 Max curvature at the pier bottom

\section{Implication of design}

In practical engineering, using friction model for the bearings is inconvenient and not supported by many design software. Therefore, the safety factor should be considered when using the result from bi-linear bearing model for the design.

\subsection{Design of the bearing}

The long-span continuous beam bridge usually employs the variable section beam, and most of the gravity load is carried by the middle bearings. Under vertical GM, the long side span behaves like a cantilever beam, so that the side bearing sustained larger fluctuation in the vertical load than the middle bearing. According to this analysis, the safety factors of 2.0 and 3.0 are approximately suggested for the middle and side bearings respectively, when selecting the bearing type based on their gravity loads. In practical engineering, the required safety factors of the middle and side bearings are related to the distribution of the spans and weights. The longer and lighter side spans may intensify the cantilever effect. In a word, the fluctuation of bearing depended on the gravity sharing, i.e. the span layout of the bridge. It should be noticed in the future study.

The maximum horizontal restoring force presented strong linear correlation with the peak compressive load. The maximum restoring force can be the product of the peak compressive load and friction coefficient. Thus, the most critical state for the bearing was the coupled compressive and shear load, which achieve the peak values at the same 
time. The coupled vertical and horizontal loads for the connection design were $\gamma G$ and $\mu \gamma G$, where $\gamma$ was the safety factor and $G$ was the compressive load caused by gravity. When the $I R$ was smaller than 1.05, the deformation demand didn't have evident increase. According to some major seismic design codes, the suggested $I R$ was smaller than 1.0, so that the deformation demand obtained from the bi-linear bearing model can be used in the design.

\subsection{Design of the pier}

The analysis indicated that the maximum lateral drift of the pier was not proportional to the maximum restoring force of the bearing. For example, at the $I R$ of 1.05 , the frictional bearing provided the maximum restoring force of $288.7 \mathrm{kN}$, about 1.4 times of the yielding force of the bi-linear bearing. However, the maximum lateral drift with the frictional bearing was 3.11 times of that with the bi-linear bearing. The peak compressive strains also delivered the multiples of 1.39. Currently, the peak strains at the pier bottom didn't present the intuitive proportional relationship when using the frictional bearing instead of the bi-linear bearing. As a simplified way, the amplified factor of the maximum curvature can be taken as 5.5 for the conservative design.

\section{Conclusion}

This paper conducted the quantitative comparison on the seismic performance of the continuous beam bridge with the nonlinear frictional bearing model, which employed the frictional model for the bearings, involving the fluctuation of the normal pressure and the corresponding variation of the frictional restoring force. Two 3-span continuous beam bridge numerical models were firstly built in ABAQUS with respective consideration of different bearing models, i.e. novel frictional bearing model and classic bilinear bearing model. Then the seismic performance of bridge were compared and assessed using the incremental dynamic analysis. The results indicated that by employing the frictional bearing model, the seismic performance of the bearings and piers were significantly different with those employing the bi-linear bearing model. For middle bearing under IR equaling to 3.0, the maximum vertical load was about 1.51 times of the gravity load. While side bearing subjected to 2.54 times of the gravity load under the same IR. Compared with the yielding force in the bi-linear model, the maximum restoring force obtained from the friction model were respectively 1.57 times and 2.41 times for the middle and side bearings. Besides, the peak compressive strain and tensile strains of frictional bearing model were both larger. The bi-linear model may underestimate the earthquake risk. Some major conclusions are provided as follow:

1) Even the intensity ratio (IR) of the vertical ground motion was very small, the seismic performance of the bearing and pier were different when using frictional bearing model and bi-linear model for the bearings. When the IR equaled to 0.65 , the peak restoring force and the maximum deformation of frictional model in side bearing were up to 2.24 and 1.19 times of that in the bi-linear model, respectively. Moreover, the twin-pier subjected to the larger peak tensile strain in the frictional model. Therefore, the bi-linear bearing model led to the unsafe estimation of the representative continuous beam bridge; 
2) The safety factor should be taken into account sufficiently for bearings in this continuous beam bridge. For this continuous beam bridge, the safety factors of 2.0 and 3.0 were suggested for the middle and side bearings in the bearing design, both for the vertical compressive load and horizontal shear load;

3) Employing the bi-linear model of the bearings significantly underestimate the seismic demand of the piers. For this 3-span continuous beam bridge, the amplified factors of maximum drift, maximum curvatures at the pier bottom were 3.0 and 5.5 respectively, when using the result from the bi-linear model for the pier design;

4) The safety factors for the bearings and piers may be different when the span and weight distribution of the main beam changed. The safety factor should be determined according to the actual bridge situation. And it is worth mentioning that the fluctuation of the bearing is related to the span layout of continuous girder bridge. Further study is needed for the generalized comparison considering the overall structures of the continuous beam bridge.

Abbreviations

PGA: Peak ground acceleration; FPS: Friction pendulum system; IR: Intensity ratio; DBE: Design-based earthquake; MCE: Maximum considered earthquake; MSE: Mean squared error; GM: Ground motion

\section{Acknowledgments}

Not applicable.

\section{Authors' contributions}

Man Liao: Data curation, Formal analysis, Investigation, Methodology, Writing original draft. Bin Wu: Conceptualization, Data curation. Xianzhi Zeng: Methodology, Resources, Writing - review \& editing. Kailai Deng: Conceptualization, Data curation, Methodology, Resources, Writing - review \& editing. All authors read and approved the final manuscript.

\section{Funding}

This study is supported by the National Natural Science Foundation of China (Grant No. 52078436).

\section{Availability of data and materials}

The data and materials in current study are available from the corresponding author on reasonable request.

\section{Competing interests}

The authors declare that they have no competing interests.

Received: 21 February 2021 Accepted: 18 April 2021

Published online: 06 June 2021

\section{References}

Bouc R (1967) Forced vibration of mechanical system with hysteresis, Proceeding of 4th conference on nonlinear oscillation. Prague, Czechoslovakia

Bozorgnia Y, Niazi M (1993) Distance scaling of vertical and horizontal response spectra of the Loma Prieta earthquake. Soil Dyn Earthq Eng 22(8):703-707. https://doi.org/10.1002/eqe.4290220805

Chen L, Zhang N, Jiang L (2014) Near-fault directivity pulse-like ground motion effect on high-speed railway bridge. J Cent South Univ 21(6):2425-2436. https://doi.org/10.1007/s11771-014-2196-9

Computers and Structures (2018), Inc. SAP2000 API Documentation. California

Deng K, Yan G, Yang H, Zhao C (2019) RC arch bridge seismic performance evaluation by sectional NM interaction and coupling effect of brace beams. Eng Struct 183:18-29. https://doi.org/10.1016/j.engstruct.2019.01.013

Ding L, Zhu H, Wu Q (2019) Seismic response and vibration transmission characteristics of laminated rubber bearings with single disorder. J Eng Mech 145(12):04019093. https://doi.org/10.1061/(ASCE)EM.1943-7889.0001675

Du X, Han Q, Li Z, Zhao J (2008) Inspiration of roads and bridges damage in mountain area in 5.12 Wenchuan earthquake. J Beijing Univ Technol 34(12):1270-1279 (In Chinese)

Eröz M, DesRoches R (2013) A comparative assessment of sliding and elastomeric seismic isolation in a typical multi-span bridge. J Earthq Eng 17(5):637-657. https://doi.org/10.1080/13632469.2013.771589

Ji X, Liu D, Sun Y, Molina Hutt C (2017) Seismic performance assessment of a hybrid coupled wall system with replaceable steel coupling beams versus traditional RC coupling beams. Earthq Eng Struct Dyn 46(4):517-535. https://doi.org/10.1 002/eqe.2801

Jiang L, Cao S, Wei B (2019) Effects of friction-based fixed bearings on seismic performance of high-speed railway simply supported girder bridges and experimental validation. Adv Struct Eng 22(3):687-701. https://doi.org/10.1061/(ASCE)EM.1 943-7889.0001675

Jiang L, Zheng L, Feng Y, Lai Z (2020) Mapping the relationship between the structural deformation of a simply supported beam bridge and rail deformation in high-speed railways. Proc Inst Mechan Eng Part F-J Rail Rapid Transit 234(10):10811092. https://doi.org/10.1177/0954409719880668 
Jiao C, Li A (2018) Research on influence of compression-only behavior of bearings on seismic response of double-decks long-span cable-stayed bridges. J Basic Sci Eng 26(2):380-390 (In Chinese)

Khoshnudian F, Motamedi D (2013) Seismic response of asymmetric steel isolated structures considering vertical component of earthquakes. KSCE J Civ Eng 17(6):1333-1347. https://doi.org/10.1007/s12205-013-0115-5

Kong D, Fan F, Zhi X (2015) Isolation research of fricition pendulum bearings in K8 single-layer reticulated domes. J Harbin Inst Technol 47(12):9-15. https://doi.org/10.11918/j.issn.0367-6234.2015.12.002 (In Chinese)

Li J, Peng T, Xu Y (2008) Damage investigation of girder bridges under the Wenchuan earthquake and corresponding seismic design recommendations. Earthq Eng Eng Vib 7(4):337-344 CNKI:SUN:EEEV.0.2008-04-002

Li Z, Zhang H, Luo Y (2018) Influence of vertical component of ground motion on seismic isolating performance of friction pendulum bearings isolated viaduct. Earthquake Eng Eng Dynamics 38(6):8-17 (In Chinese)

Liu Y, Xue S, Pan K, Li X (2016) Effect of a new friction pendulum bearing on seismic response of single-layer cylindrical reticulated shell considering pile-soil-structure interaction. J Cent South Univ 47(3):967-976 (In Chinese)

Marin-Artieda CC, Whittaker AS, Constantinou MC (2009) Experimental study of the XY-friction pendulum bearing for bridge applications. J Bridg Eng 14(3):193-202. https://doi.org/10.1061/(ASCE)1084-0702(2009)14:3(193)

Mazda T, Ohtori Y, Uno Y, Kaneko K, Tokumaru K, Naito N (2016) Seismic response evalution considering seismically isolated bridges using bilinear double target model. J Japan Soc Civil Eng Ser A1 72(4):I_993-I_1004. https://doi.org/10.2208/ iscejseee.72.1_993

MIDAS Soft (2019) Midas civil: integrated solution system for bridge and civil engineering. MIDAS Information Technology Co. , Ltd www.MidasUser.com

Ministry of Housing and Urban-Rural Development of the People's Public of China (2018) Rubber isolation bearings for building (JG/T 118-2018) (In Chinese)

Ministry of Transport of the People's Republic of China (2008) Guidelines for seismic design of highway bridges (JTG/T B0201-2008) In Chinese

Ministry of Transport of the People's Republic of China (2020) Specifications for seismic Design of Highway Bridges (JTG/T 2231-01-2020) In Chinese

Park YJ, Wen Y, Ang HS (1986) Random vibration of hysteretic systems under bi-directional ground motions. Earthq Eng Struct Dyn 14(4):543-557. https://doi.org/10.1002/eqe.4290140405

Systèmes D (2007) Abaqus analysis user's manual. Simulia Corp, Providence, p 40

Wei B, Dai G, Wen Y, Xia Y (2014) Seismic performance of isolation system of rolling friction with springs. J Cent South Univ 21(4):1518-1525. https://doi.org/10.1007/s11771-014-2092-3

Wei B, Yang T, Jiang L, He X (2018) Effects of friction-based fixed bearings on the seismic vulnerability of a high-speed railway continuous bridge. Adv Struct Eng 21(5):643-657. https://doi.org/10.1177/1369433217726894

Wen Y (1976) Method for random vibration of hysteretic system. J Eng Mech Div ASCE 102(2):249-263. https://doi.org/10.1 061/JMCEA3.0002106

Wilson JC (2003) Repair of new long-span bridges damaged by the 1995 Kobe earthquake. J Perform Constr Facil 17(4):196205. https://doi.org/10.1061/(ASCE)0887-3828(2003)17:4(196)

X U T, Zheng D, Yang C, Deng K (2018) Seismic performance evaluation of damage tolerant steel frame with composite steelUHPC joint. J Constr Steel Res 148:457-468. https://doi.org/10.1016/j.jcsr.2018.05.023

Yang H, Pang Y, Tian S, Dang X, Yuan W (2017) Case study of the seismic response of an extra dosed cable stayed bridge with cable sliding friction aseismic bearing using shake table tests. Struct Design Tall Spec Build 26(16):e1398. https://doi. org/10.1002/tal.1398

Zhang Y, Guo P, Dong J, Zhu C (2009) Optimization of base-isolated structure with LRB under vertical earthquake. J Harbin Inst Technol 41(12):190-193 (In Chinese)

Zhao C, Duan J, Zeng X, Deng K, Guo J, Yang S, Wen Q (2021) Considering frictional slippage at saddle-cable interface in seismic behavior of a suspension bridge. Adv Struct Eng 24(5):995-1008. https://doi.org/10.1177/1369433220974778

Zhou Z, Zhou Y, Zhao G (2003) Statistical analysis of peak ratios and response spectra of near-field accelerogrames. Earthq Eng Eng Vib 22(3):16 (In Chinese)

Publisher's Note

Springer Nature remains neutral with regard to jurisdictional claims in published maps and institutional affiliations.

\section{Submit your manuscript to a SpringerOpen ${ }^{\circ}$ journal and benefit from:}

- Convenient online submission

- Rigorous peer review

- Open access: articles freely available online

- High visibility within the field

- Retaining the copyright to your article

Submit your next manuscript at $\boldsymbol{\nabla}$ springeropen.com 